\title{
Marriage will (continue to) be the key to the future of fertility in Japan and East Asia
}

\author{
Setsuya Fukuda ${ }^{1, *}$
}

\section{Introduction}

Determinants of fertility differ across countries, and, to some extent, across regions with shared social, economic, political, and cultural backgrounds. Therefore, I would like to refine the theme, "What is likely to be the most important factor influencing future fertility trends?", by limiting my geographical focus to Japan, the country I am mainly studying. But my research on Japan is also relevant to other East Asian societies that have similar cultural backgrounds and fertility trends shaped by similar socioeconomic developments: ${ }^{2}$ namely, South Korea, Taiwan, and, to some extent, mainland China. These countries share, to varying degrees, family norms influenced by the tradition of Confucianism and its emphasis on patriarchal parent-child relationships, gender-based role specialization, and hierarchal relationships based on seniority (Cheng 2020). The region also includes countries/regions with some of the world's lowest fertility rates: Taiwan (TFR: 0.90 in 2010), South Korea (TFR: 0.98 in 2018), and Japan (TFR: 1.25 in 2005). I would like to use this opportunity to share some thoughts on why fertility is so low in East Asia by (primarily) examining Japanese data; and to discuss what I see as being the most important determinant of future fertility trends in Japan and other East Asian countries.

\footnotetext{
${ }^{1}$ National Institute of Population and Social Security Research, Tokyo, Japan

${ }^{*}$ Correspondence to: Setsuya Fukuda, fukuda-setsuya @ipss.go.jp

The views expressed in this article are those of the author, and should not be taken as those of National Institute of Population and Social Security Research or the Japanese government.

2 For a detailed overview of fertility and family patterns across East Asia, see Frejka et al. (2010) and Raymo et al. (2015).
} 


\section{Marriage as a primary predictor of fertility in Japan (and East Asia)}

In my view, the most important factor influencing fertility trends in Japan - and most likely in other East Asian countries as well - has been and continues to be marriage. In the following, I will elaborate on this view by providing some empirical evidence.

First, it is clear that marriage is essentially the only type of union in which couples have children in Japan and in East Asia. The proportion of births outside of marriage in Japan was only $2.2 \%$ in 2017, up from $0.8 \%$ in 1980 (Ministry of Health, Labor and Welfare (hereafter, MHLW) 2018). Similarly, in South Korea, the proportion of births outside of marriage increased from 1.1\% in 1981 to just 1.9\% in 2017 (Korean Statistical Information Service 2019). The very high share of marital births in East Asia makes singlehood a strong proxy for childlessness. At the same time, the timing of marriage strongly influences completed levels of marital fertility in Japan. The female mean age at first marriage has been increasing continuously since the early 1970s, rising from 24.2 in 1970 to 29.4 in 2014, and levelling off thereafter. As a result of this trend, the completed fertility of married women in Japan - which is measured as the average number of children born to women in a first marriage who have been married for 15-19 years - was stable from 1982-2002 (1982: 2.23, 2002: 2.23), but has declined slightly since then, and had fallen to 1.94 by 2015 (National Institute of Population and Social Security Research (hereafter, NIPSSR) 2017a).

The extremely low prevalence of extramarital childbearing in Japan can be seen as a cultural norm (Hertog and Iwasawa 2011), but it can also be explained from a legal point of view. A large share of the growth in non-marital childbearing in Western societies is attributable to increased childbearing within consensual unions; thus, the prevalence of non-marital childbearing is at least partly related to the legal status of non-marital consensual unions (Perelli-Harris and Sánchez Gassen 2012). Although scholarly attention to this issue has been lacking, common-law marriage in Japan is a legally defined consensual union that is comparable to non-marital unions in Western countries. Couples in common-law marriages intend to live as spouses, even though their relationship is not legally registered as married. The prevalence of common-law marriage relationships in Japan is not fully known, as the civil registration of such unions is not required, and these couples are often recorded as "married" in censuses or in other representative social/demographic surveys. In Japan, common-law marriage is similar in form to legal marriage. For example, the couples in these relationships share a residence and have legal obligations to provide mutual economic support and sexual exclusivity. Couples in common-law marriages in Japan are also entitled to the same social security benefits as married couples, 
such as national health insurance, pension, and other public assistance benefits. ${ }^{3}$ However, the marital benefits in the taxation system do not apply to couples in common-law marriages. When dissolving their relationship, the partners in a common-law marriage are also entitled to the same legal rights as married couples, such as the right to divide their mutual assets or to claim compensation if the other partner is responsible for the dissolution. But, in general, union dissolution is easier in common-law marriage than in legal marriage in Japan because the dissolution of a common-law marriage does not require the use of formal administrative procedures to deregister the marriage in the family register system.

However, legal marriage and common-law marriage differ significantly in terms of the legal protections and legal rights they confer, not only with respect to the relationship, but to the couple's children. First, whereas the right of inheritance from a deceased partner is based on agreements made by the couple in a commonlaw marriage, the partners in a married couple are automatically entitled to inherit from one another. Second, and most importantly, when a child is born within a common-law marriage, the child is registered as "illegitimate," and the custody of the child is awarded exclusively to the mother. By contrast, when a child is born to married parents, the mother and the father automatically share custody. Furthermore, a newborn child of parents in a common-law marriage needs to be recognized by the biological father in order to receive obligatory support from him. Without this recognition, the child would not even have a right to inherit from the biological father. In addition to these differences, the existence of a common-law marriage relationship is often difficult to prove because there is no official record of this relationship, particularly if both parties contribute to the social security system separately. Moreover, the distinction between common-law marriage and unmarried cohabitation is rather fuzzy, as it is based solely on whether the partners "consider" their relationship to be an alternative to legal marriage. Therefore, claiming the legal rights associated with common-law marriage is not straightforward, especially when the partners are in conflict with each other. Thus, under current civil law in Japan, there is little incentive for couples, and for women in particular, to have a child outside of legal marriage.

\section{Is there any change in the marriage-fertility nexus?}

As I discussed above, marriage is currently the only broadly accepted setting for childbearing among Japanese couples, and there is little indication that non-marital

\footnotetext{
3 To claim these benefits, the partners need to inform their workplaces (or, to be more precise, their colleagues who are in charge of employee social benefits) that they are in a common-law marriage, because employers in Japan are legally obliged to manage the collection and provision of social security contributions/benefits among their employees. However, given the low prevalence of common-law marriage in Japan, couples in such unions are often reluctant to declare their relationship to their workplaces, as it may be considered socially deviant, and represent a risk to their reputations.
} 
childbearing is becoming more common in Japan, or is likely to do so in the future. However, this does not necessarily mean that marriage will continue to be an important factor in future fertility in Japan. In fact, there are slight but important signs of changes in the pathways to marriage and fertility within marriage. In this section, I will describe these new trends, and examine whether they signal the emergence of some broader changes in the marriage-fertility nexus.

\subsection{Cohabitation}

The very low percentage of births outside of marriage implies that the options for forming an alternative union are limited for couples looking to start a family in East Asia. Surveys show that only 1.7\% (2015) of young adults aged 18-34 in Japan are currently living in a non-marital union (excluding common-law marriage) (NIPSSR 2017a). The proportions of young adults who have ever experienced cohabitation are, not surprisingly, somewhat higher. For example, the proportion of never-married men and women aged 25-29 in Japan who have ever had a cohabiting relationship increased from $4 \%$ in 1987 to $10 \%$ in 2005, and then levelled off until 2015. However, the same survey also shows that the proportion of married women who had cohabited with their current spouse before marriage increased from $10 \%$ of the women marrying in 1990-1994 to 33\% of the women marrying in 2005-2010 (own calculation from the 14th Japanese National Fertility Survey (hereafter, JNFS)). These figures suggest that cohabitation in Japan is becoming increasingly common among women who marry. In addition, the large gap in the prevalence of cohabitation experience between the married and the never-married population clearly suggests that cohabitation in Japan serves as a prelude, rather than an alternative, to marriage. Currently, however, this increasing trend in premarital cohabitation is unlikely to alter the rigid order of marriage and childbearing in Japan.

\subsection{Premarital pregnancy}

Pregnancy has long served as a strong motivation for unmarried couples in Japan to marry. The share of first births resulting from premarital pregnancies (adjusted by the mother's age) increased from $18 \%$ in 1995 to $28 \%$ in 2002, and levelled off thereafter (MHLW 2010). The proportion of first births resulting from premarital pregnancies is also larger among younger than older mothers (82\% at age 15-19, $64 \%$ at age $20-24,25 \%$ at age $25-29,12 \%$ at age $30-34$, and $10 \%$ at age $35+$ in 2009) (MHLW 2010). It is important to keep in mind that the close linkage between marriage and childbirth in Japan (and, likely, in other East Asian countries) is partially due to the tendency to "legitimate" premarital pregnancies. Thus, marriage cannot be seen entirely as a "determinant" of fertility. It is also very likely that marriage rates have declined in part because young men and especially young women do not feel ready to enter parenthood, with all the expectations, duties, 
and obligations it entails (Tsuya and Mason 1995). In other words, the causal link between marriage and fertility runs both ways. In this sense, the role of marriage as a "determinant" of fertility is not independent, but is, rather, highly intertwined with fertility decisions. However, it should also be noted that most women in Japan are projected to marry by age 50 (82\% in the 1990 birth cohort) (NIPSSR 2017b). Assuming that levels of non-marital childbearing continue to be low, the reversed causation or inter-related process of marriage and fertility pertains to the first birth only. Therefore, the timing and prevalence of marriage would still be the most powerful proximate determinant of fertility in Japan, particularly for second- and higher-order births.

\subsection{Decline in marital fertility and increase in marital instability}

The view that marriage is an important proximate determinant of fertility rests in part on the assumption that marital fertility is stable over time. However, the strong two-child norm reported by the cohorts of Japanese women who married before the 1980s has since been fading. A tendency to delay the first birth after marriage is becoming increasingly apparent among women who have married since the 1990s, even after controlling for the age at marriage (Fukuda 2007). Substantial delays in the transition to parenthood among married women are expected to result in increasing numbers of married women ending up having only one child (NIPSSR 2017b). The trend in marital fertility is, therefore, likely to be more important in determining future levels of fertility.

Another important trend influencing marital fertility is the declining stability of marriages in Japan. For instance, the divorce rates per 1,000 married women age 30-34 increased from 2.2 in 1960 to 14.4 in 2010, and then declined slightly to reach 13.6 in 2015 (NIPSSR 2019). Based on the period divorce rates around 2000, around one-third of Japanese marriages are estimated to end in divorce (Raymo et al. 2004). Remarriage rates per 1,000 divorced or widowed women aged 35-39 show a similar trajectory, increasing from 14.2 in 1960 to 60.0 in 2010, and then declining to 54.6 in 2015 (NIPSSR 2019). Due to the general increase in divorce and remarriage rates, the share of new marriages that were second or later marriages for at least one of the spouses increased from 15\% in 1980 to 27\% in 2015 (MHLW 2018). Although previous studies on marital fertility in Japan have focused entirely on the fertility of first-married couples, the prevalence of divorce and its consequences for remarriage and fertility have become critical factors to consider when evaluating the potential impact of marriage and marital fertility on future fertility trends.

My review generally confirms that while marriage continues to play a major role as a proximate determinant of fertility in Japan, there have been some important changes in pathways to marriage, levels of marital fertility, and the stability of marriage. The extent to which marriage can be seen as a proximate determinant of fertility in Japan depends on how these trends develop in the future. 
One of the challenges policy-makers seeking to increase East Asian fertility face is the expansion of the unmarried and non-partnered population. Indeed, Japanese data show that growing shares of young adults are not even in a dating relationship: among never-married survey respondents aged 18-34, 70\% of men and 59\% of women indicated that they had no dating relationships in 2015 (NIPSSR 2017a). Studies have suggested that the prevalence of work-related stress and the decline in the economic standing of young adults are partially responsible for this trend (Genda and Saito 2007; Nakamura and Sato 2010). However, other factors that may contribute to the decline in dating relationships among young people are not well understood. While most policy efforts to increase fertility focus on promoting childbirth among married couples, it is very difficult to directly promote marriage or even dating among young adults via public policies.

\section{What is the most important factor influencing future marriage trends?}

Assuming that marriage continues to play a major role in determining fertility trends in Japan and East Asia, what is the most important factor influencing marriage trends?

A large body of research has examined the relationship between education and first marriage in East Asia. Education appears to be one of the most important factors influencing marriage rates. Participating in education provides young people with opportunities to meet potential partners. Educational attainment serves as a proxy for longer-term earnings potential and economic stability (Blossfeld and Timm 2003), and determines the timing of marriage. Indeed, the expansion of male and female tertiary education and the decline in first marriage are among the most prominent social changes in East Asia.

One of the consistent findings regarding East Asian marriage trends is a negative educational gradient in female marriage, which is thought to reflect gender role specialization based on the male breadwinner/female homemaker model of marriage (Blossfeld and Timm 2003). However, recent studies have shown a weakening or even a reversal of this relationship in Korea (Park and Lee 2017), Hong Kong (Zhou et al. 2017), Taiwan (Cheng 2014), and Japan (Fukuda et al. 2019). My recent study with colleagues illustrated that during the 1990-2015 period, the negative educational gradient in female marriage in Japan first disappeared around 2005, and then turned positive after 2009 (Fukuda et al. 2019). This shift in the educational gradient was brought about by a combination of a decline in the marriage rates of less educated women and an increase in the marriage rates of highly educated women. The former finding is consistent with expectations derived from theories on globalization and labor market bifurcation (e.g., the concentration of non-standard employment in less educated groups); whereas the latter finding is consistent with predictions stemming from the gender revolution framework, including the 
expectation that highly educated women have a more advantaged position on the marriage market (Fukuda et al. 2019). These patterns of change are generally consistent with trends documented in the U.S. and in many other wealthy countries. It should be noted that the ideational shift toward dual-earner marriage - which is likely to be facilitated by both economic uncertainty and the preference for more gender-equal sharing of economic roles - will be an important factor influencing marriage trends in Japan, and possibly in other East Asian societies in which highly educated young adults have become a majority in the marriage market. Given these findings, it is likely that policies aimed at supporting female employment and workfamily balance will have a positive impact on both marriage and childbearing.

\section{Conclusion}

In this short article, I provided my thoughts on the factor that is most likely to influence future fertility trends in Japan, while drawing on a wide range of available data. My conclusion is that marriage continues to be the most important proximate determinant of future fertility in Japan, and, arguably, in other East Asian societies as well. Marriage itself is being affected by the trends in female tertiary education and the concurrent shift toward a dual-earner marriage ideology. However, I am aware that future fertility trends may not conform to a simple extrapolation of current fertility behaviors. For instance, young adults' dating behaviors and the pathways to marriage are changing; marriage has become less stable; and marital fertility is declining. These changes may also reshape the link between marriage and fertility trends in the future.

\section{References}

Blossfeld, H.-P. and A. Timm 2003. Who marries whom?: Educational systems as marriage markets in modern societies. Dordrecht, Netherlands: Kluwer Academic Publishers.

Cheng, Y. A. 2014. Changing partner choice and marriage propensities by education in post-industrial Taiwan, 2000-2010. Demographic Research 31(33): 1007-1042. https://doi.org/10.4054/DemRes.2014.31.33

Cheng, Y. A. 2020. Ultra-low fertility in East Asia: Confucianism and its discontents. Vienna Yearbook of Population Research 18: 83-120. https://doi.org/10.1553/ populationyearbook2020.rev01

Frejka, T., G. W. Jones and J.-P. Sardon 2010. East Asian childbearing patterns and policy developments. Population and Development Review 36(3): 579-606. https://doi.org/10. $1111 / \mathrm{j} .1728-4457.2010 .00347 . \mathrm{x}$

Fukuda, S. 2007. The Socioeconomic status of women and marital fertility in postwar Japan: Effects of education, employment and family structure on parity transitions. The Journal of Population Studies 40: 79-100. https://doi.org/10.24454/jps.40.0_79 
Fukuda, S., J. M. Raymo and S. Yoda 2019. Revisiting the educational gradient in marriage in Japan. Journal of Marriage and Family. https://doi.org/10.1111/jomf.12648

Genda, Y. and J. Saito 2007. Shigoto to Sekkusu no aida (Between work and sex). Tokyo: Asahi Shimbun Company (in Japanese).

Hertog, E. and M. Iwasawa 2011. Marriage, abortion, or unwed motherhood? How women evaluate alternative solutions to premarital pregnancies in Japan and the United States. Journal of Family Issues 32: 1674-99. https://doi.org/10.1177/0192513X11409333

Korean Statistics Information Service 2019. Live births by marital legitimacy for provinces.

Ministry of Health, Labor and Welfare 2010. Vital statistics special report 2010: Abstract on birth statistics. Tokyo: Ministry of Health, Labour and Welfare (in Japanese).

Ministry of Health, Labor and Welfare 2018. Vital statistics report 2017. Tokyo: Ministry of Health, Labour and Welfare (in Japanese).

Nakamura, M. and H. Sato 2010. Naze Koibito ni meguriaenai noka?: Keizaiteki Youin, Deaino Keiro, Taijinkankeinouryoku no Sokumen kara (Why they cannot have boyfriend/girlfriend?: Perspectives from economic factors, pathways and human relationship skills). In: Kekkon no Kabe: Hikon Bankon no Kouzou (The wall against marriage: Structures of non-marriage/late marriage), eds. S. Miwa, A. Nagai and H. Sato, Tokyo: Keiso Shobo, 54-73 (in Japanese).

National Institute of Population and Social Security Research 2017a. The fifteenth Japanese national fertility survey, 2015: Results of singles and married couples survey. Tokyo: National Institute of Population and Social Security Research (in Japanese).

National Institute of Population and Social Security Research 2017b. Population projection for Japan: 2016-2065. Tokyo: National Institute of Population and Social Security Research (in Japanese).

National Institute of Population and Social Security Research 2019. Latest demographic statistics 2019. Tokyo: National Institute of Population and Social Security Research (in Japanese).

Park, H. and J. K. Lee 2017. Growing educational differentials in the retreat from marriage among Korean men. Social Science Research 66: 187-200. https://doi.org/10.1016/j. ssresearch.2016.10.003

Perelli-Harris, B. and N. Sánchez Gassen 2012. How similar are cohabitation and marriage?: Legal approaches to cohabitation across Western Europe. Population and Development Review 38(3): 435-467. https://doi.org/10.1111/j.1728-4457.2012.00511.x

Raymo, J. M., L. L. Bumpass and M. Iwasawa 2004. Marital dissolution in Japan: Recent trends and patterns. Demographic Research 11(14): 395-420. https://doi.org/10.4054/ DemRes.2004.11.14

Raymo, J. M., H. Park, Y. Xie and W.-J. J. Yeung 2015. Marriage and family in East Asia: Continuity and change. Annual Review of Sociology 41: 8.1-8.22. https://doi.org/10.1146/ annurev-soc-073014-112428

Tsuya, N. O. and K. Oppenheim Mason 1995. Changing gender roles and below replacement fertility in Japan. In: Gender and family change in industrial countries, eds. K. Oppenheim Mason and A. Jensen, 139-167. Oxford: Clarendon Press.

Zhou, M., X. Wu and G. He 2017. Marriage in an immigrant society: Education and the transition to first marriage in Hong Kong. Demographic Research 37(18): 567-598. https://doi.org/10.4054/DemRes.2017.37.18 
Open Access This article is published under the terms of the Creative Commons Attribution 4.0 International License (https://creativecommons.org/licenses/by/4.0/) that allows the sharing, use and adaptation in any medium, provided that the user gives appropriate credit, provides a link to the license, and indicates if changes were made. 
